\title{
CONSIDERAÇÕES SÔBRE "GRUPOS DE PRESSÃO"
}

\author{
Edgar Ferreira Barbosa \\ Professor da Faculdade de Direito de Natal
}

\section{I - VONTADE NACIONAL - PARTIDOS POLÍTICOS - INTERESSES DE GRUPOS}

1. A variedade ou a versatilidade das fontes profundas do Direito representa uma das condições da liberdade política. Nas democracias que merecem êsse nome, tais condições se preservam pela participação de cada indíviduo na formação da vontade nacional. E nos países modernos, que adaptaram suas instituições a um mundo econômico e social cada vez mais complexo, a atuação do indivíduo não se concebe senão como intermediária e auxiliar dos órgãos de tôda ordem que o encadeiam, aprisionam, susteem e, de qualquer modo, o protegem. É através de células, grupos, sindicatos, associações - (e temos aí um regresso, em grande estilo, às corporações medievais), que a coletividade vem fazendo sentir nos seus propósitos, seus deś́gnios e sua fôrça. São essas alavancas legais ou clandestinas, abertas ou misteriosas, que agitam, enriquecem, pressionam e modificam não só os processos do Estado - mas a própria idéia do Direito. O problema urgente será conciliar a autoridade política do Estado com as exigências multiformes dos grupos, buscando assim o ponto de equilíbrio entre as necessidades nacionais ou as aspirações coletivas e os imperativos de interêsse que circundam os poderes constitucionais, tentando inspirá-los, coagí-los e dirigí-los ao sabor das reivindicações de grupos. 
2. O Estado liberal, filho das revoluções, mas cioso das suas formas de legalidade, chegou a munir-se de tão acabrunhadora regulamentação que veio ferindo, uma por uma, suas conquistas de tolerância e liberdade. PIERRE GAXOTTE, em obra clássica sôbre a Revolução Francêșa, caricaturou o Estado burocrático, apresentando-nos o autoritarismo esclarecido, sob os traços de um funcionário sentado detrás de um "bureau" com os seus cadastros, fichas, códigos, manuais, carimbos, sêlos, "tickets", passaportes, registros e outras exquesitas exigências que se ordenam sob o vago qualificativo de "canais competentes". (La Révolution Française, p. 14).

Ocorre que êsse Estado, se hipertrofiando e distendendo, não construiu por nenhum dos seus poderes orgânicos as bases adequadas para que nela se firmasse o complexo de imposições do seu tremendo desenvolvimento.

ALEXANDRE BUNGE, emérito professor da Universidade Buenos Aires, salientava há quarenta anos, do alto da sua cátedra, que, sem dúvida, o individualismo democrático da filosofia do sec. XVIII triunfara em todos os povos do sec. XIX sob o "leit motiv" da igualdade política. Mas, a carreira vertiginosa da técnica industrial produziu ou engendrou uma desigualdade econômica tanto mais penosa para as classes trabalhadoras quanto desapareciam as normas reguladoras da velha organização aristocrática. Os socialistas mais ilustrados - continuamos o pensamento de BUNGE - já não pretendiam mais destruir as "desigualdades naturais", e sim, apenas, as "desigualdades artificiais" produzidas pelos costumes, convenções, heranças e títulos.

Essa nova concepção de igualdade social é muito original, porque fundamentalmente aristocrática, acarretando o advento de organı necessidade e a fatalidade de elites tanto sociais quanto de grupos, sejam quais forem as leis decretadas pelo Estado.

Os partidos tiveram, entre os seus objetivos e programas, a disciplinação do tumulto. A democracia renovada depois da Constituição de Weimar (1919), da Constituição do México e das Cartas das democracias populares nascidas da última guer- 
ra, proclamou simultâneamente a ampla liberdade de associação (na Europa Central e balcânica, sob o controle dos govêrnos), garantindo, fomentando e protegendo os grupos profissionais ou sindicais, na forma como o fêz a nossa Carta de 18 de setembro de 1946, artigo 141, §§ 12 e 13 e artigo 159.

3. Partidos políticos e grupos profissionais, econômicos, consórcios e sindicatos, eis as fôrças postadas diante dos edifícios da organização do Estado. A vontade geral, coletiva, nacional, que seria representada pelos partidos. A vontade e os interêsses grupais, representados por elementos os mais diversos, sem caráter público, pressionando os poderes públicos.

0 individualismo de 1789 condenou os grupos, as corporações de ofício, as associações de classe, ao mesmo tempo que animou a organização dos clubes políticos, matrizes dos partidos. A história do nosso Direito Constitucional começa sob o influxo dêsse liberalismo à outrance, que coincide com a época da independência e que consistia, afinal, na assimilação e adaptação de instituições estrangeiras pelas elites nacionais e na experiência, mais ou menos bem sucedida, do emprêgo dessas instituições sôbre um povo até certo ponto inabilitado para praticá-las ou até mesmo compreendê-las.

Os partidos políticos nacionais sofrem êsse mal de origem, por mais inspirados que sejam os seus líderes no desejo e salvaguarda do bem comum. Não têm fôrça ideológica, dispersam-se na vontade dos homens que os dirigem, perdem-se em alianças eventuais, esfacelam a representação aos golpes do personalismo, como bem observou HERMES LIMA em recente conferência no Conselho Técnico da Confederação Nacional do Comércio. (Carta mensal do C. T. da Confederação Nacional do Comércio, julho 1958, n. ${ }^{\circ} 40$ ). Falta-lhes, pois, ousamos di. zer, certa unidade de sentimento, homogeneidade na luta, diria mesmo, certa coragem da aventura política, a que Nabuco se referia quando descreveu o drama chileno da Presidência Balmaceda.

4. É ocioso demorar-me sôbre as causas dessa crise ou nos motivos porque os partidos políticos brasileiros consentem na interferência ostensiva ou secreta dos grupos e organizações 
extra-partidários. Reportar-me-ia ao magnífico estudo do eminente AFONSO ARINOS DE MELO FRANCO, apresentado ao IV Congresso Jurídico Nacional, realizado em São Paulo em janeiro de 1955: - é o sistema eleitoral, é a inflação corrompendo o voto, são os próprios grupos partidários, arrastados pelas correntes dos interêsses sociais criados, "são aquêles blocos cuja existência FRANÇOIS GOGUEL procurou identificar no decurso de tôda a vida da Terceira República Francêsa e que designou com os nomes de Ordem e Movimento".

Tal classificação exprime eloquentemente idéias representadas ou simbolizadas por outras palavras como - Progresso €. Retrocesso; Revolução e Reação; Exaltação e Moderação; Radicilismo e Conservadorismo; Nacionalismo e Entreguismo, as quais povoam de páginas mais ou menos apaixonadas, a literatura política e a oratória parlamentar de tantos países, a começar pelo nosso.

Ilustrando êste acêrto, direi que talvez mais poderosamente do que no resto do mundo, na França o jôgo político é o jôgo dos partidos. É em nome dos partidos que os candidatos enfrentam o colégio eleitoral, é exprimindo a vontade dos seus partidos que os deputados sustentam ou renegam os Ministérios. É ainda no seio dos partidos que se coagulam e se organizam as doutrinas e tendências que dividem a opinião. Mas, também na França, no pano de fundo da política partidária, caracterizada pela multiplicidade, não se agitam, não crescem, não pressionam o govêrno sòmente os partidos. Sindicatos de trabalhadores, sindicatos patronais, consórcios, organizações corporativas, grandes emprêsas privadas, associações de antigos combatentes, movimentos de juventude, sociedades intelectuais, igrejas, universidades, exercem, como testemunha MAURICE DUVERGER, imensa influência sôbre a vida político-administrativa. São organizações que agem na sombra, e através delas se revela um dos traços característicos da contraditória ética política moderna, que é a dissimulação. Uma parte da vida política se desenrola nas ribaltas da mais espetacular publicidade. Mas, a outra parte, fermenta e flui, como um rio subterrâneo, no "underground" dos segrêdos de gabinete, nos reposteiros oficiais. 
5. Assim, a vontade nacional outorgada aos partidos políticos sofre as traições, omissões e ausências da atrocidade individualista - como que há uma subrogação de deveres arrebatados ou usurpados pelos grupos mais organizados, mais astuciosos, mais sorrateiros, que se infiltram nos negócios públicos em nome dos seus interêsses.

Poderíamos esquematizar essas considerações do seguinte modo:

$10^{0}$ - Sistema eleitoral e a inflação do voto enfraquecem os partidos;

$2 .^{\circ}$ - Não havendo partidos nacionais como a Constituição os previu, as agremiações políticas se subdividem, se regionalizam, tornando-se presa dos grupos;

$3 .^{\circ}$ - Os grupos fazem as eleições, comandam a vontade política, aliam-se ou guerreiam-se livres de qualquer controle de idéias, de sentimentos coletivos, e combatem pelos seus interêsses de classe ou de conveniência econômica.

\section{II - O ADVENTO DOS GRUPOS DE PRESSÃO - CONDI- ÇõES POLÎTICAS, ECONÔMICAS E PSICO-SOCIAIS.}

1. A Democracia moderna denuncia cada vez mais intensamente a estrutura unitária do poder, do que é exemplo a tendência do refôrço do Executivo, tendo como consequência a perda de independência dos outros poderes. Nos Estados Unidos, conforme observa uma escritora de Direito Público das mais argutas, a Sra. LÊDA BOECHAT RODRIGUES (A Côrte Suprema e o Direito Constitucional Americano), os problemas constitucionais criados pela primeira Guerra Mundial não chegam, durante o conflito, até a Côrte Suprema. "Wilson domina o Congresso e estabelece importantes precedentes no sentido da iniciativa legislativa e da extensão da autoridade presidencial. $\mathrm{O}$ govêrno controla os preços, as estradas de ferro, as linhas telefônicas e telegráficas, o comércio marítimo, as habitações e o trabalho; implanta o racionamento de certos alimentos e de combustíveis, torna-se o maior empregador do país. 
A concentração de poderes no Presidente acompanhada de considerável alargamento da autoridade federal".

"O efeito nervoso da guerra, o choque da revolução russa, a falta de preparo para amplas divergências intelectuais, contribuem para a onda de intolerância que inunda o país após o conflito e se reflete no Congresso".

Depois de 1929, nos Estados Unidos, e, consequentemente, em maior ou menor escala, no mundo ocidental, multiplica-se o movimento de concentração de capitais. Devemos recordar que, na última metade do século XIX, a tendência dessa corrida centralizadora era o "monopólio". Em nossa época, por meio das atividades dos "grupos de pressão", das fôrças dos clichês e slogans publicitários, das contribuições e verbas especiais, os efeitos políticos dêsses consórcios e associações se tornam mais relevantes que os próprios efeitos econômicos.

Chegamos à idade de franca participação na vida política do "architecrum fallaciarum", e se dermos aos têrmos corriqueiros seu verdadeiro significado, as expressões "relações públicas", "businessman" e equivalentes, encontram-se no dicionário analógico dos grupos de pressão.

0 americanismo lobbying, isto é, a atividade de determinadas pessoas que agem em nome de grupos interessados na votação de determinadas leis e na execução, ou não, de certas medidas, chega a ser considerado, indiscutivelmente, a expressão mais importante, embora equívoca, do direito de petição. $\mathrm{E}$ êsse fenômeno, em relação ao Legislativo nos Estados Unidos, mereceu reparo de uma autoridade como D. W. BROGAN, que em seu livro "An Introduction to American Politics (págs. $349 / 350$ ), aseverou que, embora sem contrôle, particulares e grupos de pressão, em tôda parte, procuram influênciar o trabalho legislativo .

2. Apareceram, nos últimos cincoenta anos, condições políticas, econômicas e psico-sociais que vieram favorecendo a irrupção dos grupos de pressão no campo retalhado pelas guerras internacionais ou civís . 
A concentração do poder econômico, segundo nos mostra ADOLF BERLE JUNIOR em livro de 1954 (citado pela Sra. LEDA BOECHAT RODRIGUES na obra a que já nos referimos), desempenhou papel importante na criação de um clima em que o indivíduo prefere não pensar, não discordar, não levantar questões desagradáveis, não chocar ou desagradar o grupo em que se move. "Espalhou-se a idéia" - comenta ADOLF BERLE JUNIOR - "de que qualquer expressão de personalidade "controvertida" prejudica a perfeição do ideal do homem integrado numa organização. $\mathrm{E}$ então, na indústria, nos bancos, nas maiores instituições educacionais, até no govêrno, quando o nome de alguém está em foco para nomeação ou promoção, o pior que se pode dizer dêle é ser a sua personalidade "controvertida". Isso significa, apenas, que algures, em qualquer momento, essa pessoa teve ou expressou idéias reprovadas por algum grupo. E qualquer minoria organizada, capaz de espalhar boatos, de instigar campanhas, de movimentar antipatias, pode tornar qualquer personalidade objeto de opinião "controvertida", pelo simples fato de atacá-la.

3. Se é certo que a Constituição atribui o poder, não garante, por sí só, que êste venha a ser exercido. Para que se exerça o poder, a condição si ne qua é a substância do valor-homem. E quando MONTESQUIEU escrevia que a virtude deve ser a mola real das Democracias, o mundo se achava no século XVIII - ROUSSEAU exaltava com demasiado otimismo as belezas da natureza humana. Antes dêles, MAQUIAVEL já preconizara a aplicação na política e no govêrno de uma outra forma de virtude, a "virtú", a malícia, a astúcia, o envolvimento, o amaciamento, os fins que justificam os meios, a tirania solérte, meândrica, adormecedora... .

Interessados no contrôle menos exigente do Estado, fundam-se emprêsas, organizam-se grupos, delineam-se consórcios. Uma variedade infinita de "societas", para o bem e para o mal, para o jôgo das influências e para a advocacia de interêsses específicos, pressionam os poderes constituídos, impedem a uniformização das leis, tornam cada vez mais complexo o sistema de discriminações, previlégios, concessões e favores. 
Vemos aí as razões do advento dos grupos de pressão, que se afiguram uma fatalidade da, conjuntura democrática, uma diátese irremediável dos poderes do Estado moderno. Quando a direção, o comando e o planejamento nem sempre vêm de cima, e sim dos lados, das induções de fora, rompe-se a solidariedade social. E hoje em dia, torna-se mais cômodo ao poder político cercear igualdades e direitos coletivos, do que opôr-se às exigências crescentes dos grupos.

4. Como bem doutrina BURDEAU no seu "Manuel de Droit Public (titre II, pág. 151), "Em face dos grupos o império do Estado é infinitamente mais reduzido, porquanto êles se situam em condições de lhe opôr uma fôrça da mesma ordem que a sua. Os grupos, por isso mesmo que se organizam em tôrno de um fim comum, dão origem a um poder no qual se encarnam aspirações realistas. E tão bem o fazem que, no duelo que se estabelece entre o Estado e os grupos, cria-se naturalmente um antagonismo de poderes. Antagonismo que coloca o poder estatal, instrumento da idéia do direito oficial, ante os poderes de fato, cujos fins rivalizam com aquêles perseguidos pelos govêrnos, mas que se apoiam em fôrças controladas pelos mecanismos do Estado. O problema do Iugar destinado aos grupos no Estado, surge, assim, em face da coexistência dos poderes de fato com o poder de direito. Seguramente, tal situação não s€ apresenta sempre, em relação a todos os grupos, sob o mesmo aspécto ou com iguais sutilezas. Mas, o fato de que ela tende a estabelecer rivalidades ou emulações entre grupos e poderes constituídos, prova que foi ultrapassado o limite jurídico em que se sistematizaria a questão, sob a rubrica - "liberdade de associação", que é um aspécto particular das liberdades individuais".

\section{III - CLASSIFICAÇÃO DOS "GRUPOS DE PRESSÃO" - LEGITIMIDADE DÊSSES GRUPOS - POSIÇÃO DA AMERICA LATINA, ESPECIALMENTE DO BRASIL.}

Pode-se, na verdade, classificar elementos heterogêneos, dispersos, alguns dêles até imponderáveis? Há uma Constitui- 
ção que setrutura ideològicamente o Estado; organiza-se o poder, definem-se as competências, configuram-se as atribuições, delimitam-se os deveres e os direitos. Há poderes implícitos, inscrevem-se como garantias de sobrevivência do regime o intervencionismo, o dirigismo economico, a proteção social, a previdência, o amparo dos mais fracos. Surgem então, desencadeados pela atrocidade do meio, os quistos do organismo estatal, fôrças estranhas que vêm cobrar seu tributo à democracia e que por vêzes são aceitas como legítimas e decorrentes da contingência econômica e social.

Em luminosa conferência que proferiu sôbre a atuação dos "grupos de pressão" no regime brasileiro, o Professor TEMíSTOCLES CAVALCANTI citou o Prof. PRICE, autoridade americana que vincula a existência dos grupos de pressão às formas corporativas de govêrno que antes e durante a última guerra floresceram na Europa, com espírito mais soreliano, e cujas tentativas se ensaiaram no Brasil. Tais grupos corporativos, alimentados pela ideologia totalitária, não eram mais do que interêsses organizados que se identificavam do Estado. E foi assim que tivemos, nos países corporativistas, a predominância legal e a liderança política dos grupos que se substituiam aos partidos políticos.

2. A história das crises modernas nos mostra (e sôbre êste assunto é indispensável a leitura da obra de GAETANO MOSCA completada por GASTON BOUTHOUL, "História das Doutrinas Políticas"), que não existe sistema político invulnerável à ação dos "grupos de pressão", ação que se faz sentir sobretudo onde não se conta com uma forte opinião pública ou com um sistema eficaz de separação dos poderes. Em tais circunstâncias, o dirigismo econômico facilita e proporciona a influência ou a atuação mais direta de grupos poderosos, que se infiltram nas esferas governamentais.

Como classificar essas fôrças, algumas delas tão estranhas, anônimas e imperceptiveis?

3. Valho-me da enumeração organizada por TEMíSTOCLES CAVALCANTI, talvez o primeiro, no Brasil a tratar objetivamente do problema em conferência a que já me reportei, pro- 
nunciada no Conselho Técnico da Confederação Nacional do Comércio (Carta Mensal do C. T. da Confederação Nacional do Comércio, maio 1958, n. ${ }^{\circ} 38$ ). Diz o ilustre tratadista:-

Procurei (para os grupos de pressão), uma classificação tirada dos trabalhos do Prof. Lavaus, de Finer e de Hirsch Webber. Elles fizeram várias classificações, e eu procurei tirar dessas uma que me parece relativamente satisfatória. Evidentemente que não concluí aquí alguns grupos ou algumas organizações que poderiam ser consideradas como tais. Lembro-me que em Pittsburg, na reunião da Associação Internacional de Ciência Política, era eu o único representante de país latino-americano. Perguntaram-me lá se as Fôrças Armadas poderiam ser consideradas "grupos de pressão" no Brasil e na América Latina. 0 debate se generalizou, tomando, naturalmente, aspécto científico, porque não havia outro intuito senão procurar qualificar a natureza das intervenções, e, posteriormente, também saber quais eram as orientações da participação das Fôrças Armadas na vida política do país e quais os seus objetivos.

Dêsses debates resultou alguma coisa muito interessante, porque o Prof. Hirsch-Webber tinha estado na Bolívia durante muito tempo e dava uma interpretação diferente da minha em relação ao Brasil. Eu chamava a atenção para o fato de que nas intervenções que nossas Fôrças Armadas tiveram na vida política do nosso país, nunca haviam assumido o poder diretamente. Apenas pressionavam para atingir os objetivos que tinham em vista, coisa que não se dava na Bolívia.

O Prof. Finer deu sua interpretação de que, naturalmente, a estrutura social do Brasil e da América Latina não eram bastante sólidas, o que permitia que surgissem elementos com participação muito direta na vida política do país, como a igreja e as Fôrças Armadas, o que, realmente, não está longe de ser verdadeiro.

Darei a classificação que tínhamos preparado, de acôrdo com as propostas apresentadas por Finer, Lavaux e Hirsch-Webber:- 
1 - Grupos de pressão da Indústria, do Comércio e da Agricultura;

2 - Trabalho;

3 - Profissionais;

4 - Cívicos;

5 - Sociais;

6 - Religiosos;

7 - Recreativos;

8 - Educativos e Culturais.

Nessas oito categorias estão incluídas as associações e confederações da Indústria e do Comércio, e as associações agrícolas, que imprimem, dispensando o veículo dos partidos políticos, forma orgânica à representação dos seus grupos. Desfilam, na segunda categoria, os sindicatos de classe e associações operárias, constituindo agremiações que atuam decisivamente sôbre a estrutura política e burocrática, graças ao número e à união dos seus componentes. Vêm, em seguida, os agrupamentos profissionais de advogados, engenheiros, médicos, funcionários públicos, professôres, estudantes, jornalistas, muitos dos quais, na defesa das suas reivindicações, chegam até ao concurso da greve. As demais, são as que têm finalidades cívicas ou religiosas, como a Liga de Defesa Nacional, a Liga Eleitoral Católica, as Associações de Municípios, as de fundo esportivo, cultural ou beneficente, as academias e instituições científicas, entidades que defendem interêsses próprios, e que não deixam de ser grupos representativos de fôrças atuantes na vida política e na esfera administrativa.

4. Aparentemente distantes do aglomerado nacional, mas interferindo com império na evolução político-econômica, vislumbram-se as organizações internacionais, os "trusts", sindicatos e consórcios que têm agido como fatores decisivos até o ponto de têrmos que considerá-los como categoria sociológica fundamental na história dos povos sul-americanos.

Em livro publicado em 1956, o sociólogo peruano EUDOCIO RAVINES focalizou o intervencionismo estrangeiro em nosso continente, tendo expressões como estas:- 
"Os consórcios estrangeiros são promotores do bem e do mal em nossa América Latina. Sua história é a mesma dos pioneiros e dos piratas. Têm sido missionários e bucaneiros, criadores e espoliadores. Tanto enriqueceram como empobreceram os povos onde plantaram as suas tendas de vanguardeiros da civilização industrial. Todo consórcio é responsável pelo nível de vida dos trabalhadores que emprega, na moradia que habitam, da saúde ou das doenças das zonas que ocupam. E ao mesmo tempo essas organizações são responsáveis, também, pela conduta das autoridades nativas frente à população. Tornam-se entidades mescladas ìntimamente à existência latino-americana, seja para o bem, seja para o mal. Suas funções abarcam a totalidade, e assim elas têm sido progressistas e benéficas em alguns momentos, regressivas e prejudiciais em outros.

"A consequência natural é que, na América Latina, seus povos e seus govêrnos têm de enfrentar o problema dos consórcios estrangeiros como qualquer dos seus grandes problemas nacionais. E já então o consórcio não pode ser avaliado como um bem ou um mal exterior, senão como assunto intern. $\epsilon$ doméstico, obrigado a vincular mais e mais seu destino do bem estar geral do país onde propera".

5. Concluímos aceitando, com reservas e a devida vênia, a classificação organizada pelo douto TEMíSTOCLES CAVALCANTI. Mas, permitindo-nos duvidar da legitimidade de grupos de qualquer origem ou natureza, eredenciados ou não para a interferirem na vida Legislativa, Judiciária ou Executiva da Nação. O imperialismo nativo ou alienígena, ao parasitar a árvore onde se implantou, parecerá, por algum tempo alimentá-la e rejuvenecê-la com as suas floradas. Mas, em seguida, a trôco de concessões que ferem o cérne e comprometem a livre manifestação da vitalidade nacional, terminam jungindo-a à sua própria fortuna, aos interêsses do seu mercantilismo e aos manejos da sua astúcia.

6. Deveríamos ainda definir as características próprias dêsses grupos, identificando-os pela sua organização interna, pela sua ação sôbre a opinião pública; pelas influências que exer- 
cem nos pleitos políticos, nas decisões econômicas, nos poderes e órgãos da administração. Entretanto, deixo aos especialistas, aos pensadores políticos, aos que meditam sôbre o destino da Pátria forrados da cultura sociológica e do sentimento do passado, a caracterização exata e definitiva dessas potências que alçam o colo na realidade econômica, social e política brasileira.

\section{IV - CONSIDERAÇõES FINAIS}

1. O Brasil não está sòzinho a sofrer as influências e induções dos grupos empenhados em conquistar os mais diversos setores da política, da economia, da cultura, da administração pública. Na vertigem do nosso crescimento, bracejamos na maré legislativa, procuramos fórmulas e esboçamos soluções que disciplinem o complexo nacional. Penetramos na idade da especialização e da técnica, tentamos mecanizar e ordenar o nosso mundo. Caucheiros do extremo Norte, pescadores e vaqueiros do Nordeste, usineiros do açucar, industriais do cacáu, homens de emprêsa de São Paulo e do Rio, fazendeiros de Minas, desbravadores de Goiás e Mato Grosso, bandeirantes, novos, que fincaram o desafio do Brasília, construtores dær magnifica civilização do Paraná, estancieiros do Rio Grande do Sul, todos marcham pelo bem da Pátria e não desejam nem esperam que a liberdade lhes seja tolhida por interêsses do egoísmo e da insatisfação dos grupos máus. Os bons não se mascaram nem muito menos distorcem a legalidade, pois, mais do que nunca, e assim disse ainda há pouco GILBERTO AMADO, os homens de bôa vontade e puros ideais confiam em que a política nacional adquira objetividade, procurando ligar os efeitos às causas.

2. Se me fôsse dado guardar alguma ilusão sôbre o valor dêste trabalho, sentir-me-ia feliz se a palavra de louvor que êle merecesse atraisse as atenções dos mais dignos de tratarem do problema, do qual fui apenas pobre e aventuroso repetidor. 


\section{BIBLIOGRAFIA}

1 - PAULINo JACQUES - Curso de Direito Constitucional, ed. Revista Forense, Rio, 1958.

2 - PIERRE GAXOTTE - La Révolution Française.

3 - HERMES LIMA - Conferência na Confederação Nacional do Comércio, julho de 1958.

4 - AFONSO ARINOS DE MELO FRANCO - Os partidos políticos nacionais, IV Congresso Jurídico Nacional, 1955.

5 - MAURICE DUVERGER - Le Droit Constitutionel e les institutions politiques.

6 - LEDA BOEChAT RODRIGUES - A Côrte Suprema e o Direito Constitucional Americano - Ed. Revista Forense, Rio, 1958.

7 - 'D. W. BROGAN - An Introduction to American Politics.

8 - GEORges BURDEAU - Manuel de Droit Public - Ed. R. Pichon et R. Durand-Auzias, Paris, 1948.

9 - TEMISTOCLES CAVALCANTI - Conferência na Confederação Nacional do Comércio, in Carta Mensal do C. T. da Confederação Nacional do Comércio, maio 1958, n. ${ }^{\circ} 38$.

10 - EUD6CIO RAVINES - América Latina - Um continente em Erupção. 